\title{
COMO BURRO NO ARENOSO: AS CONTRADIÇÕES DA FORMa em "Cara-De-Bronze" DE GUIMARÃEs Rosa
}

\author{
Emmanuel Santiago*
}

Resumo

O intuito deste trabalho é abordar a problemática envolvendo a integração do Brasil no mundo do capitalismo industrial (e seus impactos sobre a realidade regional dos gerais mineiros) e como essa problemática está por trás dos princípios constitutivos pelos quais se organiza a estrutura formal de "Cara-de-Bronze", novela de Guimarães Rosa.

Abstract

This work aims to approach the issue of Brazil's integration within the world of industrial capitalism (as well as its impacts on the regional reality of Minas Gerais' people), and to discuss the way this issue is behind the basic principles that organize the formal structure of the short story "Cara-de-Bronze", by Guimarães Rosa.
Palavras-chave

Guimarães

Rosa; forma

literária;

processo

social;

narrativa

brasileira.

Keywords

Guimarães

Rosa; literary

form; social

process;

brazilian

narrative.

* Mestrando em Teoria Literária e Literatura Comparada (FFLCH-USP). 
m dos pontos centrais de "Cara-de-Bronze", ${ }^{1}$ a partir do qual todos os demais núcleos temáticos da novela serão abordados, é a interlocução entre os vaqueiros do Urubuquaquá e os integrantes de uma comitiva responsável pela compra do gado da fazenda. Dentre estes, está Moimeichêgo que, ao conduzir a conversa com os vaqueiros "numa maiêutica digna de Sócrates com seus discípulos", 2 provoca um enfrentamento de perspectivas, como no seguinte trecho em que se discute a aparência física de Segisberto Jéia Velho Filho, o misterioso fazendeiro conhecido entre os seus funcionários como o Cara-de-Bronze:

Moimeichêgo: E - o homem - como é que ele é, o Cara-de-Bronze?

O vaqueiro Adino: Ara, é um velho, baçoso escuro, com cara de bronze mesmo, uê!

Moimeichêgo: Você já viu bronze?

O vaqueiro Adino: Eu? Eu cá, não, nunca vi. Acho que nunca vi, não senhor. Mas também eu não fui que botei o apelido nele...

Moimeichêgo: Quem pôs? (Silêncio de todos. Pausa) ${ }^{3}$

Enquanto para Adino o saber constituído coletivamente e transmitido pela tradição não é alvo de problematização, para Moimeichêgo parece no mínimo inusitado que se atribua a alguma coisa uma propriedade de algo que se desconhece, no que este representa o pensamento moderno, fundado na autoridade da expe-

${ }^{1}$ ROSA, Guimarães. "Cara-de-Bronze". Corpo de baile. Ed. comemorativa. Rio de Janeiro: Nova Fronteira, 2006, p. 558-627. 2 vols. Todas as indicações de página da novela correspondem a esta edição.

${ }^{2}$ ESPÍRITO-SANTO, Rosana Silva do. "Cara-de-Bronze': mosaico dos gerais". In: DUARTE, Lélia Pereira et al. (Org.). Veredas de Rosa II. Belo Horizonte: PUC Minas/ CESPUC, 2005, p. 700.

${ }^{3}$ ROSA, Guimarães. "Cara-de-Bronze". Corpo de baile. Ed. comemorativa. Rio de Janeiro: Nova Fronteira, 2006, p. 574-5. 
riência e da reflexão individuais em contraposição à tradição. Nesse sentido, Moimeichêgo assume a mesma função do doutor silencioso de Grande sertão: veredas, que consiste em materializar um ponto de vista citadino, o ponto de vista da cultura letrada, no interior do universo rural. ${ }^{4} \mathrm{O}$ mesmo ocorre com o título da novela, e também apelido de sua personagem principal, pois, ao coloquialíssimo termo "cara", empregado ao invés do convencionalmente mais literário "face", contrapõe-se o bronze, material tido como nobre e repleto de conotações eruditas. Essa mesma dualidade se verifica na intrincada tessitura formal da novela, na qual coexistem formas típicas do cantar e do contar populares, de natureza oral, com formas da cultura letrada, como notas de rodapé, e um roteiro cinematográfico.

"Cara-de-Bronze", tanto em suas soluções formais quanto em seus temas, oferece um instantâneo literário do processo de modernização da sociedade brasileira que se dá a partir da incorporação de elementos pré-modernos relacionados ao nosso passado colonial. Mais especificamente, "Cara-de-Bronze" trata do momento, apreendido de dentro do universo rural, em que se tenta introduzir o Brasil do século XX na órbita do capitalismo industrial. Somos colocados, logo de início, a par da situação do Cara-de-Bronze "tencionando apurar tudo o que tem, no bom dinheiro" (p. 564), marcando a passagem de um modelo produtivo baseado no trabalho rural para um modelo monetário, no qual a posse do dinheiro vale mais do que a posse sobre a terra. Como se sabe, no Brasil, foram as oligarquias rurais as responsáveis pela introdução de práticas e valores da modernidade burguesa, o que lhes garantiu a manutenção de seus interesses de classe. ${ }^{5}$ É o que acontece também em nossa novela, pois, ainda que esteja vendendo todo o gado de sua fazenda, o Cara-de-Bronze coloca um de seus funcionários em "testamentos herdados" (p. 627), perpetuando o latifúndio, já que, segundo as palavras do vaqueiro Sacramento, "nessas suas terras, ele agarra" (p. 564). A imagem do proprietário que faz a passagem para a economia de mercado, mas que ainda se mantém "agarrado à terra", ou seja, às bases do sistema latifundiário, é bastante significativa no que se refere ao processo de modernização da sociedade brasileira. Com isso, o apelido dado à personagem ganha nova dimensão, pois, se o bronze é um material conhecido pela sua resistência contra o tempo, Segisberto, por sua vez, sofre de uma doença degenerativa que se supõe ser a lepra (p. 589). Descontando-se o evidente humor negro do apelido, este, quando contraposto à condição física do fazendeiro, revela o caráter persistente e ao mesmo tempo decadente do patriarca. Ligado a uma ordem obsoleta, que se esperaria ultrapassada pela modernização da sociedade brasileira, o grande latifundiário ainda hoje é uma figura muito presente e influente em nosso cenário político e econômico. Podemos dizer que, em alguma medida, o Cara-de-Bronze representa o patriarcado brasileiro nessa transição perpétua para a ordem burguesa.

${ }^{4}$ Cf. ARRIGUCCI-JR., Davi. O mundo misturado: romance e experiência em Guimarães Rosa. In: PIZZARRO, Ana (Org.). América latina: palavra, literatura e cultura. São Paulo: Memorial; Campinas: UNICAMP, 1995, p. 463, v. 3.

${ }^{5}$ Cf. HOLANDA, Sérgio Buarque de. Raízes do Brasil. 26. ed. São Paulo: Companhia das Letras, 1995, p. 71-92. Em especial o terceiro capítulo, "A herança rural”. 
O arranjo formal pouco ortodoxo de "Cara-de-Bronze" visaria a dar conta de uma experiência "não canônica"6 da modernidade, pressentida num de seus momentos mais críticos, a década de 50 para a sociedade brasileira. A região que serve de referência para a criação do universo ficcional rosiano, os gerais mineiros, surge então como uma zona de contato entre os influxos modernizantes e os fundamentos do sistema latifundiário, o que gera um problema de ordem mimética que traz profundas consequências para a estrutura formal de nossa novela. Diante de uma realidade regional crivada de traços modernos, as velhas estratégias narrativas do regionalismo literário não dão mais conta da complexidade de seu objeto; é o que se verifica na composição da voz narrativa de "Cara-de-Bronze" que assume um caráter fantasmagórico. Esse caráter se verifica no fato de que, ainda que interaja com as personagens e lhes emule a dicção, a voz narrativa não chega nunca a se concretizar em personagem, mantendo-se no âmbito do puro artifício literário e sem se configurar como "efeito de realidade", como algo ficcionalmente determinável dentro da ação da novela:

Não. Há aqui uma pausa. Eu sei que esta narração é muito, muito ruim para se contar e se ouvir, dificultosa; difícil: como burro no arenoso. Alguns dela vão não gostar, quereriam chegar depressa a um final. Mas - também a gente vive sempre somente é espreitando e querendo que chegue o termo da morte? Os que saem logo por um fim, nunca chegam no Riacho do Vento. Eles, não animo ninguém nesse engano; esses podem, e é melhor, dar volta para trás. Esta estória se segue é olhando mais longe. Quem já esteve um dia no Urubuquaquá? ${ }^{7}$ (grifo nosso)

As palavras grifadas revelam a intenção de integrar o texto no ambiente das narrativas tradicionais, pois esta não é uma história que se escreve e se lê (ainda que o seja de fato), mas uma narração que se conta e se ouve. Além disso, ao se comunicar diretamente com os leitores, a voz narrativa cria o cenário para uma narração oral, convertendo os seus receptores numa comunidade de ouvintes. ${ }^{8}$ Com a finalidade de configurar o material regional, a voz narrativa se identifica com as formas tradicionais da região, representadas na ação da novela pela narração do Grivo, no falatório dos vaqueiros e nas trovas do cantador João Quantidades. No entanto, tal voz, ainda que chegue a influir sobre o que as personagens estão dizendo - como no caso das intervenções que faz durante a narração do Grivo num discurso que não se pode determinar precisamente se direto ou indireto (discurso indireto livre) -, não chega a se materializar como personagem, ocupando uma espécie de limbo entre o enunciado e a enunciação: ${ }^{9}$

${ }^{6}$ Expressão cunhada por Roberto Schwarz para definir a experiência brasileira com a modernidade. Cf. SCHWARZ, Roberto. Discutindo com Alfredo Bosi. Sequências brasileiras. São Paulo: Companhia das Letras, 1999, p. 70.

${ }^{7}$ ROSA, Guimarães. "Cara-de-Bronze". Corpo de baile. Ed. comemorativa. Rio de Janeiro: Nova Fronteira, 2006, p. 588.

${ }^{8}$ BENJAMIN, Walter. O narrador: considerações sobre a obra de Nikolai Leskov. Magia e técnica, arte e política: ensaios sobre literatura e história da cultura. Tradução de Sergio Paulo Rouanet. 2. ed. Rio de Janeiro: Brasiliense, 1986.

9 "Os narradores gostam de começar sua história com uma descrição das circunstâncias em que foram informados dos fatos que vão contar a seguir, a menos que prefiram atribuir essa história a 
- Chapadão de Antônio Pereira?

Virou dessas travessias.

- Sempre nos Gerais?

- Por sempre. O Gerais tem fim?

Ao que são campinas e chapadas e chapadões e areiões e lindas veredas e esses escuros brejos marimbús - o mato cerrado na beira deles. ${ }^{10}$

No trecho que acabamos de ler - no qual o primeiro e o segundo travessão indicam a fala dos vaqueiros, e o terceiro indica a do Grivo -, a voz narrativa oferece uma síntese das respostas virtuais deste último num discurso indireto que mais parece direto, dada a falta de referência interna ao discurso da personagem. Logo adiante, a voz narrativa passa a inquirir o Grivo, motivando o seu relato naquilo que talvez seja o discurso indireto das perguntas dos vaqueiros, embora aqui e ali revele algo que estes não poderiam saber:

O Grivo alguma vez parou, duvidou. Que-maneira hesitou?

- Tenho costume de tristeza: tristeza azul tarde, água assim. Tenho um medo de estar sem companheiro nenhum; não tenho medo deste mundo sendo triste tão grande...

Estava só. E as árvores?

- As árvores são cabeças de vento...

Alguma saudade?

- A saudade é braço-e-mão do coração, e que, certas horas, quer segurar demais em alguma pessôa ou coisa. Mas, não se deve-de...

Ele era bobo ${ }^{11}$

Essa espécie de narração em dueto persiste por grande parte do relato do Grivo e, ainda que a utilização do discurso indireto livre seja bastante recorrente na literatura moderna, a sua utilização em "Cara-de-Bronze" produz um efeito de estranhamento causado por essa voz que vem não se sabe de onde e à qual as personagens parecem responder sem se darem conta disso, por isso lhe atribuímos um caráter fantasmagórico que revela em todas as suas contradições a ambiguidade de um discurso que, embora emule uma narração oral, destina-se a ser lido individualmente, explorando de maneira radical as possibilidades técnicas e formais que a forma escrita lhe põe à disposição. Encarando a obra de Rosa como um passo além no regionalismo, como pretende Antonio Candido, ${ }^{12}$ podemos

uma experiência autobiográfica". Cf. BENJAMIN, 1986: p. 205. Uma das convenções que caracterizam o narrador tradicional é a sua "materialidade" dentro do universo em que se passa a sua história, o que costuma ser reproduzido na forma escrita. A voz narrativa de "Cara-de-Bronze", ao contrário disso, não se configura como um narrador determinado e, mesmo se dirigindo ao seu leitor e interagindo com as personagens, mantém-se sempre como uma fantasmagoria da qual estas não podem se dar conta e a qual o leitor não pode delimitar ficcionalmente.

${ }^{10}$ ROSA, Guimarães. "Cara-de-Bronze". Corpo de baile. Ed. comemorativa. Rio de Janeiro: Nova Fronteira, 2006, p. 603.

${ }^{11}$ Idem, ibidem, p. 605-6.

${ }^{12}$ CANDIDO, Antonio. Literatura e subdesenvolvimento. A educação pela noite e outros ensaios. São Paulo: Ática, 1987, p. 161-2. 
pensar na voz narrativa de "Cara-de-Bronze" como uma síntese que, ao invés de resolver, problematiza os moldes consolidados de representação da matéria regional. Segundo Antonio Candido, duas atitudes são constantemente verificadas na composição de uma obra regionalista: ou esta se estrutura numa "dualidade estilística" em que o tom se divide entre a prosa em norma culta do narrador, de tipo acadêmica, e a representação de uma fala pitorescamente estilizada atribuída às personagens, como ocorre no regionalismo de um Coelho Neto, por exemplo; ou acontece uma "identificação máxima com o universo da cultura rústica" e o enfoque narrativo recai sobre uma primeira pessoa pertencente ao universo representado, como se dá na obra de Simões Lopes Neto. ${ }^{13}$ A voz narrativa de "Cara-de-Bronze" oscila entre essas duas soluções, pois, embora se identifique com o universo regional, não o faz completamente, o que a impede de se materializar como personagem no interior da obra, preservando o seu distanciamento e um certo grau de onisciência, traços de sua natureza de expediente literário sem substancialidade ficcional. Em outras palavras, fica entre uma perspectiva externa à região, como forma literária ligada ao âmbito da cultura letrada e ao universo da escrita, e uma perspectiva interna obtida através da emulação estilizada de uma narração oral. Assim, também a voz narrativa se configura a partir das contradições do processo de modernização da sociedade brasileira, estabelecendo uma dinâmica entre o arcaico e o moderno em que a falta de uma conciliação entre os dois termos causa o estranhamento de uma voz da qual não se sabe se vem de dentro ou de fora do espaço ficcional - o que corresponde a questionar se tal voz parte ou não de dentro do universo regional, onde os elementos pré-modernos de nossa formação histórica são bem mais evidentes e pronunciados.

Um fato aparentemente sem maior importância, uma "bobaginha" nos dizeres do autor, recebe então um novo redimensionamento: em sua correspondência com Edoardo Bizzarri, Guimarães Rosa revela que "o nome MOIMEICHEGO é outra brincadeira: é: moi, me, ich, ego (representa "eu", o autor)". ${ }^{14}$ Fazendo de Moimeichêgo o seu alter-ego, o escritor constrói um mise-en-abyme em que o desafio enfrentado pela personagem (tentar a mediação entre a visão citadina e o discurso dos vaqueiros) espelha o seu próprio desafio como autor: traduzir, através da mediação de uma forma escrita, a autenticidade da cultura regional para os padrões citadinos de apreensão da realidade. Nesse contexto, a forma dramática atua como maneira de apresentar a realidade regional em seus próprios termos, de maneira que é no enquadramento dramático da ação que o leitor toma contato com as formas do contar e do cantar populares. A identidade cultural da região, portanto, não aparece em função de um discurso narrativo que lhe sirva de moldura, mas, ao invés disso, destaca-se deste através da forma dramática, como um alto-relevo.

13 Idem. A literatura e a formação do homem. Textos de intervenção. (Org.) Vinícius Dantas. São Paulo: Duas Cidades; Ed. 34, 2002, p. 87-92.

${ }^{14}$ BIZZARRI, Edoardo (Org.). J. Guimarães Rosa: correspondência com seu tradutor italiano Edoardo Bizzarri. 2. ed. São Paulo: T. A. Queirós / Instituto Cultural Ítalo-Brasileiro, 1981, p. 61. 
Ao se delimitar dramaticamente, o universo regional se oferece como espetáculo, algo a ser captado por uma perspectiva. Essa perspectiva é a do leitor, sim, mas é também a da cultura letrada, com a qual este se identifica. Não se trata simplesmente de apresentar um registro dramático da situação - como ocorre no diálogo presumido entre Riobaldo e o doutor silencioso que serve de esquema narrativo para Grande sertão: veredas -, mas de uma mediação do âmbito da cultura oral para o da letrada feita através da inclusão de rubricas e notas de rodapé. A função do autor como mediador entre a cultura regional e a letrada fica muito clara numa outra aparição "hitchcockiana" de Rosa dentro de sua obra; numa das notas de rodapé, que - num tom explícito de pastiche de texto acadêmico - refere-se a uma variação da canção executada no primeiro plano por João Quantidades, um tal de Soares Guiamar é citado como tendo catalogado outras variantes dessa mesma canção. ${ }^{15}$ Soares Guiamar é um anagrama de Guimarães Rosa, ${ }^{16}$ o que significa que, nas duas vezes em que aparece no texto, o autor é aquele que tenta apreender a realidade regional a partir do ponto de vista da cultura letrada.

O roteiro cinematográfico é o ápice desse procedimento contraditório em que, quanto mais imediata se supõe a apresentação do material regional, mais mediado é esse material pelas formas escritas, pois, além de configurar o universo regional como algo a ser captado por determinada perspectiva, trata-se de um roteiro, forma escrita, ao qual não faltam sequer as indicações técnicas. O recurso à forma dramática cria a ilusão de uma imediação do conteúdo narrado, ao mesmo tempo em que, com a inclusão de rubricas, notas e indicações técnicas, despedaça-se tal ilusão. Não podemos deixar de reparar que, se a voz narrativa se dirigia ao seu público incluindo-o na comunidade de ouvintes de uma narrativa tradicional, as formas que apresentam dramaticamente a cultura regional, com suas notas e rubricas, destinam-se a um leitor familiarizado com a "alta cultura" ocidental, capaz de dar sentido às citações de Platão, Dante e Goethe trazidas a reboque da narração do Grivo através do rodapé do texto. Essa confusão na atribuição de papéis, ao leitor, pode ser a configuração literária de uma situação histórica na qual a introdução das práticas da modernidade não eliminou as condições sociais de recepção da narrativa tradicional, ao contrário do que teria acontecido na Europa ${ }^{17}$ no que se manifesta o caráter peculiar de nossa experiência com a modernidade, da qual "Cara-de-Bronze" parece mais uma vez dar prova.

A complexa tessitura formal de "Cara-de-Bronze" se organiza a partir de uma vertiginosa dinâmica baseada na reversibilidade de seus elementos, segundo a qual os movimentos de sua estrutura se relacionam contraditoriamente com os demais, além de também apresentarem contradições internas, o que levou um de seus críticos a lhe atribuir uma "fraqueza estrutural, decorrente de uma falta

${ }^{15}$ ROSA, Guimarães. "Cara-de-Bronze". Corpo de baile. Ed. comemorativa. Rio de Janeiro: Nova Fronteira, 2006, p. 612.

${ }^{16}$ MACHADO, Ana Maria. Um nome que enche os tons. O recado do nome: Guimarães Rosa à luz do nome de seus personagens. São Paulo: Martins Fontes, 1976, p. 60.

${ }^{17}$ Benjamin relata a experiência de que "a arte de narrar está em vias de extinção". Cf. BENJAMIN, op. cit., p. 197. 
de rigorismo (ou demasiado rigorismo) na construção da obra". ${ }^{18}$ Nós, ao contrário, enxergamos nisso o próprio princípio estrutural da obra, atualizado rigorosamente em cada movimento seu, resultado da configuração consequente de uma realidade constituída na tensão de forças contraditórias. ${ }^{19}$ Em outras palavras, Guimarães Rosa transformou o caráter problemático de nosso processo de modernização num princípio estrutural levado às últimas consequências em "Cara-de-Bronze"; vários elementos do enredo apontam nessa direção, como o embate de perspectivas entre Moimeichêgo e os vaqueiros, a migração do oligarca para a economia de mercado, entre outros. No entanto, a crítica tem se mostrado desconcertada diante da intensa variedade formal de nossa novela, levando-a a apostar numa síntese conciliadora de suas contradições internas, ocultando na obra aquilo que deveria ser o seu maior êxito. ${ }^{20}$ Tal síntese tem sido acompanhada por uma leitura que, em detrimento de temáticas mais "universais", desconsidera os elementos da realidade social incluídos no enredo. Assim, ao oferecer uma análise conciliadora dos aspectos formais de "Cara-de-Bronze", a crítica oferece uma imagem igualmente conciliada da realidade regional e do processo de modernização da sociedade brasileira como um todo, uma imagem depurada de qualquer conflito e contradição.

[Este artigo resulta de minha pesquisa de mestrado intitulada "A narração dificultosa: forma literária e processo social em 'Cara-de-Bronze' de Guimarães Rosa” (título provisório), sob orientação da Prof ${ }^{a} \operatorname{Dr}^{a}$ Ana Paula Pacheco. Tal texto, que foi apresentado numa outra versão como trabalho de conclusão de curso na disciplina Teoria Crítica ministrada pelo Prof. Dr. Jorge de Almeida no segundo semestre de 2007, constitui o gérmen daquilo que no futuro pode ser um dos capítulos de minha dissertação.]

\footnotetext{
${ }^{18}$ MARTINS, Heitor. No Urubuquaquá em Colônia. Oswald de Andrade e outros ensaios. São Paulo: Conselho Estadual de Cultura, 1971, p. 66.

${ }^{19}$ Para José Antonio Pasta Júnior, o regime conjunto de sistemas de valor entre si contraditórios é uma marca de nosso caráter histórico, atualizado literariamente ao longo de toda a literatura brasileira. É o que se verifica em Grande sertão: veredas, caracterizado por um "estatuto da contradição insolúvel", segundo o qual o romance assume "a configuração de uma espécie de dialética negativa, que a contradição faz bascular sem parada, mas que não conhece superação ou síntese propriamente ditas”. Cf. PASTA-JÚNIOR, José Antonio. O romance de Rosa: temas do 'Grande sertão' e do Brasil. Novos Estudos Cebrap, n. 55, 2000, p. 63.

${ }^{20}$ Como acontece em "A viagem do Grivo", de Benedito Nunes, de onde a crítica posterior parece ter tirado todos os seus pressupostos ao tratar de "Cara-de-Bronze": "As variações do tempo e da mimese em 'Cara-de-Bronze', dentro de uma estrutura polimórfica, da qual participam elementos narrativos, dramáticos e líricos, produzem a impressão de intemporalidade dos relatos mitopoéticos". Cf. NUNES, Benedito. A viagem do Grivo. O dorso do tigre. São Paulo: Perspectiva, 1969, p. 187.
} 